* Mestre em Direito Negocial pela Universidade Estadual de Londrina (UEL). Pósgraduando lato sensu em Ciências Penais pela Universidade Anhanguera-Uniderp. E-mail: leonardoferreiramendes@ yahoo.com.br

** Doutor em Direito Constitucional (UFPR). Mestre em Direito e em Ciências Sociais (UEL). Professor na Pontifícia Universidade Católica do Paraná, na Universidade Estadual de Londrina e no Centro Universitário de Maringá. Email: zulmarfachin@uol.com.br

\section{Abertura sistêmica do direito civil contratual como promoção da democracia}

\section{SYSTEMIC OPENING OF CONTRACTUAL CIVIL LAW AS PROMOTION OF DEMOCRACY}

\author{
Leonardo Ferreira Mendes * \\ Zulmar Fachin **
}

Resumo: Esse texto objetiva estudar as influências da abertura sistêmica do direito contratual na promoção de uma democracia que permita a participação de todos. No primeiro tópico teceram-se considerações sobre a passagem do sistema de direito civil fechado para o aberto, e sobre a teoria tridimensional do Direito. Após, foram abordadasnoções de democracia e de cidadania participativas. Por fim, demonstrou-se que a abertura sistêmica do direito civil contratual é um instrumento poderoso para promoção de isonomia material. Concluiu-se que a sistematização fechado dificulta o acesso aos bens materiais mínimos, o que impede a construção de um Estado Democrático de Direito.

Palavras-chave: Abertura Sistêmica; Direito Contratual Civil; Democracia.

Abstract: This article intends to study the influences of the system opening of the contract in the promotion of a participative democracy. At first, it had been presented a short study about the changes from the closed private law system to the opened one, and the tridimensional law theory. After, it had been enunciated notions of participative democracy and citizenship.For last, it have been demonstrated that the system opening of the contract private law is a powerful tool to promotion of material equality. It had been concluded that the closed system model makes difficult the access to the minimum material goods, what prevents the construction of a Democratic State of Law.

Keywords: System Opening; Contract Private Law; Democracy. 


\section{INTRODUÇÃO}

O fenômeno da abertura sistêmica na codificação civil brasileira é relativamente novo. São apenas oito anos de uma codificação que visa modificar paradigmas arraigados no ordenamento brasileiro desde o início do século XX. Esse novo paradigma de engenharia legislativa acaba por produzir reflexos por todo sistema jurídico civil, não escapando dessa realidade o Direito contratual.

Aliás, não seria qualquer exagero dizer que este instituto foi um dos que sofreram maiores reflexos do modelo de sistematização aberta. Toda a lógica principiológica de outrora, baseadas no mote "liberdade" da Revolução Francesa, visava à consagração ao máximo de uma isonomia formal que tratava de igual maneira atores sociais extremamente diferentes. Velava-se pelo respeito e perpetuação da segurança das relações jurídicas, consagrando-se os princípios da autonomia privada, força obrigatória dos contratos e de sua intangibilidade. Com o transcorrer do século, parte dos rigorismos da teoria retratada foram relativizados, geralmente em prol do interesse público. Mas nada que fosse suficiente a promover a igualdade social entre os membros da sociedade brasileira, tão desiguais entre si.

Com a redemocratização brasileira e o advento da Constituição da República de 1988, foi iniciado um processo de busca da justiça social, através da irradiação de princípios que gravitam o valor Dignidade da Pessoa humana, tudo em busca da tão sonhada igualdade material. Essa busca, como não poderia deixar de ser, acabou por gerar uma séria desconformidade entre o Direito Civil de então e a normatização civil-constitucional. Diante desse quadro, foi promulgado o Código Civil de 2002, já em tramitação há quase trinta anos e que, ainda assim, não demonstrou completo descompasso com relação à sociedade que visava regular. Essa nova sistemática, no entanto, trouxe profundas consequências ao Direito contratual, socializando as relações jurídicas e exigindo boa-fé objetiva dos contratantes.

Nesse artigo pretende-se demonstrar que ambos os princípios constituem fortes instrumentos de promoção dos valores constitucionalmente consagrados, em especial da democracia, por meio da concretização de isonomia em sentido material. Para consecução de tal desiderato, em um primeiro momento foi abordada a técnica de abertura sistêmica no Direito Civil, com um breve estudo das cláusulas gerais, dos conceitos jurídicos indeterminados e dos princípios fundamentais da codificação civil, quais sejam, os princípios da eticidade, da socialidade e da operabilidade. 
A seguir, foi realizada uma abordagem sobre o delineamento moderno de cidadania, por intermédioda promoção da dignidade humana em uma sociedade multicultural, especialmente quanto à garantia dos direitos das minorias, através da consagração de direitos fundamentais. Nesse sentido, defendeu-se que democracia, tendo como centro axiológico o valor dignidade da pessoa humana, demanda que a minoria possa influenciar a ponto de, eventualmente, até mesmo se tornar maioria. Neste diapasão, para que possua efetivo poder de influência, esta minoria deve contar com direitos mínimos, como educação, saúde e segurança, muitos dos quais podem ser resumidos a um patrimônio jurídico mínimo, indispensável ao desenvolvimento das potencialidades de todo e qualquer ser humano.

No terceiro tópico foi enfrentado o cerne do problema proposto, qual seja, as consequências da abertura sistêmica para o Direito Contratual, e seu emprego como instrumento de concretização de uma democracia que permita a participação efetiva de todos seres humanos na vida social em todos seus aspectos.

Já na conclusão, foi defendido que a abertura sistêmica transforma o direito contratual em mecanismo imprescindível à consagração dos valores democráticos, em especial porque permite a busca da felicidade pelos atores sociais, por mais diferentes que sejam, independentemente de suas necessidades específicas, ideologias e orientações.

\section{ABERTURA SISTÊMICA}

A revolução industrial, duas grandes guerras e a massificação da produção e do consumo ocasionaram, ao longo do século XX, drásticas mudanças no paradigma das relações sociais como um todo, inclusive no Direito Civil (RAMOS, 1998, p.07/08). Tais fatos trouxeram grandes consequências para o macrossistema do Direito, não escapando dessa regra o Direito Civil.

Em um primeiro momento, o modelo de sistematização fechada, inspirado no Código de Napoleão, demonstrou-se incapaz de regular as relações sociais frente à diversidade dos novos paradigmas (RAMOS, 1998, p.07/08), em especial no que tange aos negócios jurídicos. O novo paradigma social relegou aos seres humanos novas possibilidades e necessidades, exigindo do Direito que se adaptasse às novas formas negociais daí decorrentes.

Ademais, o modelo de então primava pelo prestígio a uma isonomia formal exagerada, que acabava por pretender uma igualização absoluta de atores sociais 
em tudo diferentes. Assim, em prestígio à isonomia formal, aprofundavam a desigualdade material. Nesse diapasão, obtempera Michel Villey (2003, p.79):

A justiça "comutativa" também serviu de base a enormes contra-sensos. Dela extraiu-se o princípio da igualdade dos contratantes, o sistema do liberalismo, que tratando pobres e ricos de maneira eqüitativa, na verdade esmaga os primeiros. Abuso manifesto.

A codificação de 1916 mostrou-se inapta a essa adaptação, tendo em vista sua inspiração em valores positivistas, baseados nas teorias da completude e da onipotência do legislador (TEPEDINO, p.27). Daí, o surgimento de legislações esparsas, regulando relações jurídicas específicas, as quais acabaram subtraídas do sistema hermeticamente fechado do Código Civil brasileiro revogado. Conforme aduz Cláudia Lima Marques, quanto ao contrato, em comentários que são pertinentes ao Direito como um todo (2006, p.49):

A idéia de contrato vem sendo moldada, desde os romanos, tendo sempre como base as práticas sociais, a moral e o modelo econômico da época. $\mathrm{O}$ contrato, por assim dizer, nasceu da realidade social.

Com o advento da Constituição de 1988, o Código de 1916 mais uma vez mostrou-se incapaz à autoatualização, revelando grave incompatibilidade vertical com aquele diploma normativo. A Constituição da República de 1988, de um lado, tendo como centro axiológico a Dignidade da Pessoa Humana (FACHIN, 2012, p.23) e, como estrutura de engenharia legislativa, uma miríade de normas abertas (cláusulas gerais, conceitos jurídicos indeterminados e princípios); o Código Civil, de outro, tendo como núcleo o valor segurança jurídica, instrumentalizado na proteção da propriedade (MEIRELLES, p.98; FACHIN, p.13/15) e sendo estruturado, consequentemente, em uma sistematização fechada, com prevalência de normas-regra.

Todos os fatos referidos levaram à fragmentação da sistematização civil, e a uma premente necessidade da adoção de um modelo de sistematização do Direito Privado adequado à rápida mutabilidade dos paradigmas sociais e às exigências constitucionais. Voltando-se a essa lógica, foi criado o Código Civil de 2002, baseado na concepção culturalista de Miguel Reale, e em sua teoria Tridimensional dinâmica do Direito.

Miguel Reale apregoava que o ser humano é um ser cultural, historicamente situado, de modo que a cultura e, consequentemente, os 
paradigmas sociais, não são realidades estáticas (1998, p.572). Dessa feita, as normas também não podem ser estáticas, uma vez que visam regular a vida do homem em sociedade. Com tais constatações, as obras de Reale defendem que o Direito não é formado apenas por normas jurídicas, nos moldes apregoados pelos adeptos da Escola da Exegese, e dos variados autores positivistas. Na verdade, o Direito seria uma relação entre fatos e valores, relacionados por uma dialética de implicação e polaridade, relação esta que tem como resultado, as normas jurídicas. Segundo enuncia o jusfilósofo brasileiro, os três elementos influenciam-se mutuamente, em um contínuo processo de atualização normativa pela mudança dos fatos e valores de uma sociedade. Nesses casos, a norma jurídica sofre uma atualização pela mudança de sua interpretação. Se não possuir elasticidade hermenêutica suficiente para tanto, acabará sendo revogada.

Eis aí, portanto, através de um estudo sumário da experiência das estimativas históricas, como os significados da palavra Direito se delinearam segundo três elementos fundamentais: - o elemento valor, como intuição primordial; o elemento norma, como medida de concreção do valioso no plano da conduta social; e, finalmente, o elemento fato, como condição da conduta, base empírica da ligação intersubjetiva, coincidindo a análise histórica com a da realidade jurídica fenomenologicamente observada (REALE, 1998, p.509).

Essa teorização traduz toda a base filosófica da estrutura do Código Civil de 2002: pretendia-se fosse um código capaz de se autoatualizar, sobrevivendo à cambialidade da sociedade que visa regular. Com essa meta, Reale projetou o Código Civil, empregando como técnica de engenharia legislativa as cláusulas gerais, os conceitos jurídicos indeterminados e os princípios jurídicos.

As cláusulas gerais são normas com alta carga de abstração, que não trazem de antemão nem a fattispecie normatizada, nem a correspondente sanção jurídica pela desobediência à norma. Normas que possuem esta característica de engenharia legislativa trazem apenas um valor a ser seguido, de modo que sua incidência ao caso concreto e as consequências pela sua desobediência só podem ser delineadas diante de um caso concreto (AZEVEDO, 2009, p.93).

Já o conceito jurídico indeterminado "descreve conduta e sanção, mas a aplicação da regra passa pela análise do juiz sobre o texto, que contém expressão vaga e imprecisa" (AZEVEDO, 2009, p.93). Assim como as cláusulas gerais, a concreção dos conceitos jurídicos indeterminados só é possível diante de um caso concreto. 
Por fim, os princípios são normas com alta carga de abstração, que trazem consigo um valor ou uma política a ser seguida. Essa espécie normativa, após lições de Ronald Dworkin (2007, p.35 seq.) e Robert Alexy (2008, p.93 seq.), são tidas como normas jurídicas, a exemplo das regras. A diferença dos princípios para as regras está na sua forma de atuação e estrutura, uma vez que, enquanto as regras atuam através de uma aplicação exata, os princípios atuam numa perspectiva de otimização, devendo, quando de sua aplicação, ser ponderados com os demais princípios do sistema jurídico, por meio da máxima de proporcionalidade.

Nesse diapasão, ambas espécies normativas permitem uma maior justiça quando de sua aplicação ao caso concreto, haja vista que a definição de seu sentido exato dependerá da aferição das circunstâncias específicas do fato pelo aplicador do Direito. Além disso, permitem uma maior perenidade de grandes corpos normativos, possibilitando a sua atualização de acordo com os novos parâmetros e valores socioculturais.

Segundo enunciação de Miguel Reale, as bases do Código Civil de 2002 se assentam nos princípios da eticidade, da socialidade e da operabilidade. $\mathrm{O}$ princípio da eticidade tem como objetivo básico incutir nas relações privadas a necessidade de obediência a valores éticos, realizando uma abertura sistêmica do Direito Civil por meio do diálogo com os sistemas da Ética (MARTINSCOSTA, 2002, p.133), da Moral e da Filosofia. Um exemplo prático da influência desse princípio pode ser observado na positivação do princípio da boa-fé objetiva, nos arts. $113^{1}$ e $422^{2}$ do Código Civil de 2002.

De outro lado, o princípio da Socialidade busca a superação da lógica individualista-egoística que era marca da codificação passada, de modo que as relações jurídico-privadas devem se atentar para as expectativas e necessidades sociais. Com isso, o Código promove nova abertura sistêmica, fazendo com que o intérprete, quando da aplicação da norma, se atente para as expectativas sociais, econômicas e política, em especial as constitucionalmente traçadas (REALE, 2002). Pode ser exemplificado como influência dessa norma-valor a determinação de obediência ao Princípio da Função Social dos Contratos, insculpida no art. 421 do diploma privatista. ${ }^{3}$

\footnotetext{
${ }^{1}$ Artigo 113. Os negócios jurídicos devem ser interpretados conforme a boa-fé e os usos do lugar de sua celebração.

${ }^{2}$ Artigo 422. Os contratantes são obrigados a guardar, assim na conclusão do contrato, como em sua execução, os princípios de probidade e boa-fé.

${ }^{3}$ Art. 421. A liberdade de contratar será exercida em razão e nos limites da função social do contrato.
} 
Com relação ao princípio da Operabilidade, este tem como meta a facilitação da interpretação e da aplicação do código. A técnica de legislação por meio das cláusulas gerais, dos conceitos jurídicos indeterminados e dos princípios tem como uma de suas raízes axiológicas este princípio estrutural, uma vez que, a abertura semântica das normas desta espécie permite uma autoatualização das normas jurídicas frente às novas expectativas e demandas sociais (BRASIL, 2008, p.112). Dessa feita, torna o Direito Civil preparado para enfrentar o desafio de conjugar os múltiplos interesses em conflito no cotidiano, decorrentes da complexa e multicultural sociedade em que vivemos.

\section{DEMOCRACIA, PODER DE INFLUÊNCIA DAS MINORIAS E O PAPEL DO DIREITO PRIVADO}

Não se pode ignorar, ademais, o importante papel que o direito privado exerce na construção de uma democracia efetiva, que permita participação política de atores advindos de todos os grupos sociais. Nesse sentir, a ideia de democracia está umbilicalmente ligada à noção de cidadania.

A evolução do conceito de cidadania advém da superação do paradigma estatal liberal, e da passagem para o Estado Democrático de Direito. A esse respeito, Ana Maria D’Ávila Lopes, apoiada nas lições de Marshall, assevera que em meados do século XX concebia-se cidadania como "status que se concede aos membros de pleno direito de uma comunidade, sendo seus beneficiários iguais em direitos e obrigações" (MARSHALL, 1950, p.37 apud LOPES, 2006, p.22).

Do conceito revela-se que a cidadania não era encarada como um direito, e sim como um status do indivíduo. Na mesma senda, era o status que garantia ao titular igualdade de direitos e obrigações em relação aos demais membros. Adotava-se, portanto, uma perspectiva puramente formal de isonomia.

No entanto, a adoção da isonomia por um viés formal, embora apta a legitimar o conceito de cidadania referido sob o ponto de vista científicodogmático, acaba por se mostrar verdadeiro sofisma quando em confronto com a realidade social que visa regular. Os seres humanos são iguais em dignidade, mas extremamente diferentes no que se refere às características físicas, culturais, sociais e econômicas. De modo que, por contarem com diferentes características, possuem diferentes necessidades.

Nesse diapasão, o princípio da isonomia formal não se mostra apto a equalizar as diferenças advindas do multiculturalismo. Muito pelo contrário, 
ignorar as diferenças de características e de necessidades dos vários grupos humanos acaba por desigualá-los ainda mais sob o aspecto material, aprofundando as desigualdades socioeconômicas e perpetuando a disparidade de armas no jogo argumentativo da arena da "democracia". Nesse sentido, Ana Maria D’Ávila Lopes assevera (2006, p.25):

A visão estática e individualista de cidadania deve ser superada, na medida em que a experiência histórica mundial de violência, injustiça e desigualdade tem comprovado a necessidade de uma participação mais ativa dos cidadãos na construção de uma sociedade justa, com base no valor da solidariedade, essencial à sobrevivência de qualquer comunidade.

Em mesmo sentido, Bobbio assinala que “(...) las democracias se distinguen (...) con base enlamayor o menor dimensióndel igualitarismo que se extiende de laigualdad formal o ante laley a las varias formas de igualdadsustancial, propiasdelllamado Estado social." (BOBBIO, 1997, p.236-237).

Verifica-se que a mera declaração de que todos são iguais em direitos e deveres é insuficiente à configuração de uma cidadania e, consequentemente, de uma democracia que permitam a participação de todos os atores sociais, em igualdade de condições. Deve ser garantida a desigualização formal que possibilite a isonomia material, permitindo uma efetiva participação de todos, com iguais oportunidades de eleger e de influenciar os detentores do poder. $\mathrm{O}$ princípio da dignidade da pessoa humana não se compraz com a subserviência e o desrespeito às características socioculturais de uns em prol da garantia da hegemonia autoritária de outros.

Pois bem, tais constatações assumem grande importância quando da análise de outra fórmula empregada para retratar os valores democráticos. Trata-se da parêmia segundo a qual na democracia prevalece a vontade da maioria.

Note-se que do cotejo da realidade das sociedades hodiernas, o termo "maioria" quase nunca corresponde a uma significação quantitativa. No mais das vezes, a chamada "maioria", na verdade, refere-se às ideologias dos detentores do poder, reproduzidas pela maioria quantitativa, sem que esta possua

\footnotetext{
${ }^{4}$ Em tradução livre: "as democracias se distinguem (...) com base na maior ou menor dimensão do igualitarismo que se estende da igualdade formal ou ante a lei a várias formas de igualdade substancial, próprias do chamado Estado social."
} 
uma compreensão verdadeira daquele conteúdo que reproduz, bem como dos verdadeiros interesses encobertos pela camuflagem discursiva.

É por conta disso que a fórmula "vontade da maioria" muitas vezes acaba por significar o desrespeito aos interesses e às necessidades mais comezinhas das diversas "minorias", que, no caso brasileiro, correspondem à maioria quantitativa da população. Nesse ponto, assume especial relevância o caráter contramajoritário dos direitos fundamentais e das cláusulas pétreas que impedem sua restrição/supressão. Sobre o assunto, leciona Dworkin (2007, p.208/209):

A teoria constitucional em que se baseia nosso governo não é uma simples teoria da supremacia das maiorias. A Constituição, e particularmente a Bill ofRights (Declaração de Direitos e Garantias), destina-se a proteger os cidadãos (ou grupos de cidadãos) contra certas decisões que a maioria pode querer tomar, mesmo quando essa maioria age visando o que considera o interesse geral ou comum.

A efetiva concretização dos direitos fundamentais insculpidos na Constituição da República assume múltiplos papéis em nossa sociedade. Garante a defesa da dignidade da pessoa humana de toda a população, mormente daqueles que se encontram em situação de maior vulnerabilidade frente aos valores e interesses das transitórias "maiorias" detentoras do Poder estatal e, não raras vezes, também do Poder econômico.

É dessa constatação que sobreleva a importância da garantia dos direitos fundamentais quanto à construção de uma democracia material. A concretização dos direitos fundamentais, em especial nas relações interprivadas, deve ser empregada como instrumento que garanta o respeito aos interesses dessas minorias, de modo a lhes permitir influenciar na tomada de decisões dos detentores do Poder. Quanto a isso, cumpre trazer a baila as considerações de Gilmar Ferreira Mendes, em voto da decisão no Recurso Extraordinário 633703/ MG (BRASIL, 2011), sobre a Lei da Ficha Limpa.

Na citada decisão, o Professor e Ministro traz algumas considerações acerca do princípio da igualdade de chances (Chancengleichheit). Em apertada síntese do lá exposto, entende o Ministro que as minorias têm direito de resistência contra as decisões institucionais das maiorias no Poder, a não ser que lhes sejam garantidas as oportunidades para se tornarem maioria.

As conquistas possibilitadas pela isonomia formal são insuficientes para a garantia da igualdade de chances de tomada do Poder. Para tanto, devem ser 
asseguradas possibilidades de participação efetiva do jogo democrático. A esse respeito, assevera Canotilho (2003, p.288):

Em primeiro lugar, o princípio democrático acolhe os mais importantes postulados da teoria democrática representativa - órgãos representativos, eleições periódicas, pluralismo partidário, separação dos poderes. Em segundo lugar, o princípio democrático implica democracia participativa, isto é, estruturação de processos que ofereçam aos cidadãos efectivas possibilidades de aprender a democracia, participar nos processos de decisão, exercer controlo crítico na divergência de opiniões, produzir inputs políticos democráticos.

Essa participação, por sua vez, depende de condições econômicas e sociais mínimas, que garantam aos indivíduos e aos grupos organizadosoportunidades reais de alcançarem condições materiais que lhes permitam exercer poder de influência junto aos demais atores sociais. Ou seja, a garantia de um patrimônio existencial mínimo é condição sinequa non de concretização da democracia, especialmente em sociedades capitalistas, como é o caso da nossa.

O contrato assume importância ímpar nessa garantia, uma vez que é o principal instrumento de transferência de riquezas em uma sociedade (ANDRADE NETO, 2006, p.33). A democratização do direito contratual é, nesse sentir, uma importante e imprescindível ferramenta na concretização da democracia material. E um dos meios para democratização dos contratos é a abertura do sistema jurídico do direito contratual.

Isso porque a inflexibilidade dos modelos dogmáticos advindos das diversas correntes do positivismo jurídico é extremamente eficiente à mantença da isonomia formal. A igualdade material, de outra banda, demanda a possibilidade de uma maior adaptabilidade do Direito ao caso concreto e, principalmente, a diversidade de valores culturais, sociais e econômicos em disputa.

\section{CONSEQUENCIAS DAABERTURA SISTÊMICA NO DIREITO CONTRATUAL: DEMOCRACIA PELA PROMOÇÃO DA BOA- FÉ OBJETIVA E DA FUNÇÃO SOCIAL NAS RELAÇÕES PRIVADAS}

O princípio da boa-fé objetiva, decorrência, em âmbito infraconstitucional, do princípio da eticidade, demanda que nas relações jurídico-negociais as 
condutas demonstrem-se alinhadas a ditames de probidade e lealdade. A aferição do respeito a esses valores é realizada de forma objetiva, por meio da inferência sobre a adequação ou não da conduta dos contratantes a uma pauta objetiva de valores. Conforme exposição de Judith Martins-Costa (2000, p.411):

Já por "boa-fé objetiva" se quer significar - segundo a conotação que adveio da interpretação conferida ao §242 do Código Civil alemão, de larga força expansionista em outros ordenamentos, e, bem assim, daquele que lhe é atribuída nos países da commomlaw - modelo de conduta social, arquétipo ou standard jurídico, segundo o qual "cada pessoa deve ajustar a própria conduta a esse arquétipo, obrando como obraria o homem reto: com honestidade, lealdade, probidade". Por este modelo objetivo de conduta levam-se em consideração os fatores concretos do caso, tais como o status pessoal e cultural dos envolvidos, não se admitindo uma aplicação mecânica do standard, de tipo meramente subsuntivo.

A correta interpretação e aplicação deste princípio diante dos casos concretos torna-o um poderoso instrumento de difusão de valores éticos nas relações interprivadas, possibilitando a promoção de justiça social. Cite-se, como exemplo, a aplicação de um dos desdobramentos da boa-fé objetiva, qual seja, a substancial performance ou adimplemento substancial. Por meio da teoria do adimplemento substancial, impossibilita-se a rescisão de contratos que, apesar de não terem sido cumpridos em sua integralidade, o foram quase por completo. Dessa feita, preserva-se a relação contratual adimplida quase na totalidade, facultando-se ao credor apenas a busca do cumprimento das obrigações restantes (MARTINS-COSTA, 2000, p.457/460).

Por este desdobramento do princípio da boa-fé objetiva, ele restaria violado caso fosse possibilitado ao credor rescindir um contrato cumprido quase em sua integralidade, uma vez que haveria afronta aos deveres de cooperação e lealdade entre os contratantes. Promove-se, assim, a isonomia substancial em tais casos, uma vez que sem este princípio o credor teria o poder de, a seu bel prazer, extinguir uma relação contratual substancialmente adimplida.

O princípio da função social, por seu turno, demanda que os contratos se amoldem a valores socialmente prestigiados, extirpando das relações negociais a índole excessivamente individualista-patrimonialista de outrora. As relações contratuais devem se amoldar, assim, às expectativas sociais constitucionalmente traçadas, nos moldes do delineado por Claudio Luiz Bueno de Godoy (2009, p.120/121): 
(...) o ato de iniciativa privada, que o contrato ainda consubstancia, e mesmo não ilícito, propriamente, deve conter um objeto meritório, merecedor de tutela, o que ocorre na exata medida em que ele atende a valores do ordenamento, em especial, da Constituição.

O contrato deixa de ter como escopo apenas tutelar os interesses egoísticos dos contratantes, devendo contar com um perfil instrumental de promoção da Dignidade da Pessoa Humana e da prosperidade social. Não se quer dizer com isso que o contrato não possua mais a finalidade de transferência patrimonial, de acordo com os interesses dos contratantes, mas apenas que estes elementos não bastam para que seja acolhido pelo ordenamento jurídico. Nesse diapasão, um contrato que afronte aos interesses sociais constitucionalmente traçados afronta à sua função social e, por via indireta, desrespeita a Constituição Federal, mais especificamente o princípio da função social da propriedade (MARTINSCOSTA, 2002, p.157). Ainda, afronta de forma direta a Constituição quanto ao princípio da solidariedade (LISBOA, 2005, p.125/131).

Ambos os princípios curam para que haja a infiltração dos valores constitucionais nas relações privadas. Representam aberturas no sistema do direito civil contratual, que possibilitam ao intérprete realizar uma interpretação dialógica dessas normas, através do diálogo com as normas e diretrizes constitucionais e com sistemas extrajurídicos, a exemplo da ética, da moral e da política. Em especial, constituem um poderoso instrumento na concretização da eficácia irradiante dos direitos fundamentais nas relações privadas, possibilitando, assim, a promoção da dignidade da pessoa humana.

Nesse sentir, a técnica de abertura sistêmica do Direito Civil contratual aproxima os atores sociais do acesso aos bens indispensáveis a uma vida digna. Isso nada mais é do que promover a democratização a uma vida digna. Ainda, a garantia de um patrimônio mínimo traz ao cidadão condições psicológicas, educacionais e econômicas de participação efetiva e independente da vida social, o que constitui importante contribuição rumo à justiça social e à cidadania consciente.

\section{CONCLUSÃO}

De tudo quanto foi exposto, vislumbra-se que a abertura sistêmica do direito contratual é imprescindível à concretização da isonomia material, que permita o pleno desenvolvimento de todas as potencialidades dos seres 
humanos. Na esteira do apregoado por Miguel Reale, o ser humano é eminentemente cultural, e múltiplos fatores influenciam seus valores e necessidades.

Nesse diapasão, não é somente o fator tempo que demanda a flexibilidade de conformação das normas jurídicas. Os fenômenos "multiculturalismo" e "globalização" também promovem profundas mudanças dos paradigmas sociais. O Direito não pode ignorar as mudanças dos valores e dos fatos sociais. E normas regras estáticas, petrificadas, impossibilitam a perpetuação da norma posta frente à força dos fatos sociais.

O Direito do positivismo jurídico, com normas inflexíveis e que pressupõem uma isonomia formal que, do ponto de vista material, é apenas fictícia, geram outros efeitos nefastos. Tal espécie de sistematização alija os mais vulneráveis do direito à plena participação nas decisões e rumos de uma sociedade. Algo totalmente contraditório com a ideia de democracia, que tem como fundamento a participação de todos os cidadãos.

A abertura sistêmica do direito contratual é importante instrumento de equalização das forças sociais, uma vez que permite ao intérprete realizar a adequação do Direito ao caso concreto, inclusive no que atine às debilidades de um dos participantes da relação jurídica. Trata-se da justiça material que, ao irradiar seus efeitos às relações sociais, permite a constituição e a defesa de um patrimônio mínimo. É a partir desse ponto que há uma minoração da desigualdade de armas do jogo argumentativo democrático, que permite a todos os atores sociais exercer de maneira mais efetiva sua influência sobre os detentores do poder estatal.

Podem ser citados como exemplos práticos da influência da abertura sistêmica na construção e defesa de um patrimônio mínimo a aplicação dos princípios da boa-fé objetiva e da função social doa propriedade e dos contratos. Enquanto este determina que se valorize mais a função social que tão-somente o direito de propriedade, aquele permite uma maior justiça nas tratativas e no cumprimento dos contratos, como no caso da aplicação da "substancial performance" aos contratos de seguro, de compra da casa própria, dentre outros. Desta feita, opera-se uma inversão paradigmática do direito privado. Seu núcleo desloca-se do "ter" para o "ser", permitindo ao Direito a efetiva tutela e promoção da única finalidade que verdadeiramente o legítima: a dignidade da pessoa humana. 


\section{REFERÊNCIAS}

ALEXY, Robert. Teoria dos direitos fundamentais. Trad. SILVA, Virgílio Afonso da. [S. 1.]: Malheiros Editores, 2008.

ANDRADE NETO, Antonio Hamilton de Castro. Algumas considerações sobre a evolução dos contratos e de sua função social. In: ARRUDA ALVIM, Angélica; CAMBLER, Everaldo Augusto (Coords.). Atualidades de Direito Civil.v. 1. Curitiba: Juruá, 2006. p.19/50.

AZEVEDO, Fábio de Oliveira. Direito Civil: introdução e teoria geral. $2^{\mathrm{a}}$ ed. rev. e ampl. Rio de Janeiro: Editora Lumen Juris, 2009.

BOBBIO, Norberto. Democracia. In: SANTILLÁN, José Fernández (Comp.). Norberto Bobbio: el filósofo y la política. México: Fondo de Cultura Económica, 1997. p.229-238.

BRASIL. Código civil brasileiro e legislação correlata. $2^{\mathrm{a}}$ ed. Brasília: Senado Federal, Subsecretaria de Edições Técnicas, 2008. p.112. Disponível em: < http://www2.senado.gov.br/bdsf/bitstream/id/70327/14/ C\%C3\%B3digo\%20Civil\%202\%20ed.pdf>. Acesso em: 04 abr. 2011.

. Informativo do Supremo Tribunal Federal, Brasília, n. 620, 21/25 mar. 2011. Disponível em: < http://www.stf.jus.br//arquivo/informativo/ documento/informativo620.htm>. Acesso em: 27 abr. 2011.

CANOTILHO, José Joaquim Gomes. Direito constitucional e teoria da constituição. $7^{\text {a }}$ ed. Coimbra: Livraria Almedina, 2003.

DWORKIN, Ronald. Levando os direitos a sério. Trad. CAMARGO, Jefferson Luiz. $2^{\mathrm{a}}$ ed. São Paulo: Martins Fontes, 2007.

FACHIN, Luiz Edson. Teoria crítica do Direito Civil. Rio de Janeiro: Renovar, 2003.

GODOY, Claudio Luiz Bueno de. Função social do contrato: os novos princípios contratuais. $3^{\mathrm{a}}$ ed. São Paulo: Saraiva, 2009. 
FACHIN, Zulmar. Curso de Direito Constitucional. $5^{\text {a }}$ ed. Rio de Janeiro: Forense, 2012.

LISBOA, Roberto Senise. Manual de direito civil.v. 3: contratos e declarações unilaterais: teoria geral e espécies. $3^{\mathrm{a}}$ ed. rev. atual. ampl. São Paulo: Editora Revista dos Tribunais, 2005.

LOPES, Ana Maria D’Ávila. A cidadania na Constituição Federal brasileira de 1988: redefinindo a participação política. In: BONAVIDES, Paulo; LIMA, Francisco Gérson Marques de; BEDÊ, Fayga Silveira (Coords).

Constituição e democracia: estudos em homenagem ao Professor J. J. Gomes Canotilho. São Paulo: Malheiros Editores, 2006. p.21-34.

\section{MARQUES, Cláudia Lima. Contratos no Código de Defesa do}

Consumidor. $5^{\text {a }}$ ed. rev. atual. ampl. incluindo mais de 1.000 decisões jurisprudenciais. São Paulo: RT, 2006.

MARTINS-COSTA, Judith. A boa-fé no Direito Privado: sistema e tópica no processo obrigacional. $1^{\mathrm{a}}$ ed. São Paulo: Editora Revista dos Tribunais, 2000.

. O novo código civil brasileiro: em busca da "ética da situação". In:

; BRANCO, Gerson Luiz Carlos. Diretrizes teóricas do novo código civil brasileiro. São Paulo: Saraiva, 2002. p.87-168.

MEIRELLES, Jussara. O ser e o ter na codificação civil brasileira: do sujeito virtual à clausura patrimonial. In: FACHIN, Luiz Edson (coord.).

Repensando fundamentos do direito civil brasileiro contemporâneo. Rio de Janeiro: Renovar, 1998. p.87-114.

RAMOS, Carmem Lucia Silveira. A constitucionalização do direito privado e a sociedade sem fronteiras. In: FACHIN, Luiz Edson (coord.).

Repensando fundamentos do direito civil brasileiro contemporâneo. Rio de Janeiro: Renovar, 1998. p.03-29.

REALE, Miguel. Filosofia do direito. 18 a ed. São Paulo: Saraiva, 1998. 
. Visão geral do novo Código Civil. Jus Navigandi, Teresina, ano 7, n.54, 1 fev. 2002. Disponível em: $<$ http://jus.uol.com.br/revista/texto/2718>. Acesso em: 5 abr. 2011.

TEPEDINO, Gustavo. Normas constitucionais e relações de Direito Civil na experiência brasileira. In: Temas de direito civil. Tomo II. Rio de Janeiro: Renovar, 2006. p.21-46.

VILLEY, Michel. Filosofia do Direito: definições e fins do Direito. Os meios do Direito. Trad. AGUIAR, Márcia Valéria Martinez de. São Paulo: Martins Fontes, 2003.

Recebido em: 2012-04-08 Aprovado para publicação em: 2012-09-17

Como citar: FACHIN, Zulmar; MENDES, Leonardo Ferreira. Abertura sistêmica do direito civil contratual como promoção da democracia. Scientia Iuris, Londrina, v.16, n.1,p.9-24, jul.2012. DOI: 10.5433/2178-8189.2012v16n2p9. 